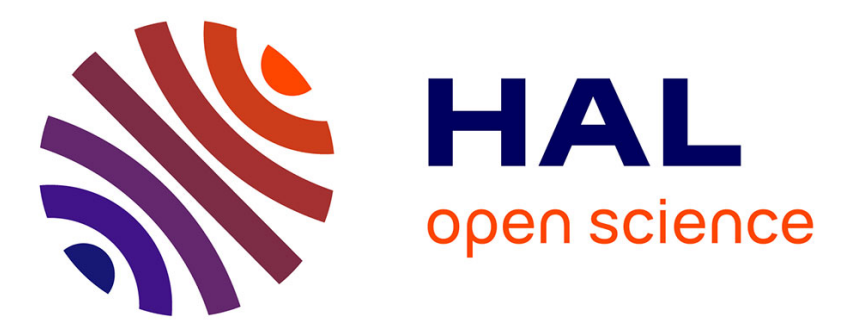

\title{
An in vitro bioassay to assess the potential global toxicity of waters on spermatogenesis: a pilot study
}

Antonine Blondet, Guillaume Martin, Laurent Paulic, Marie-Hélène Perrard, Philippe Durand

\section{To cite this version:}

Antonine Blondet, Guillaume Martin, Laurent Paulic, Marie-Hélène Perrard, Philippe Durand. An in vitro bioassay to assess the potential global toxicity of waters on spermatogenesis: a pilot study. Environmental Science and Pollution Research, 2021, 10.1007/s11356-021-12480-1 . hal-03234425

\section{HAL Id: hal-03234425 \\ https://hal.science/hal-03234425}

Submitted on 25 May 2021

HAL is a multi-disciplinary open access archive for the deposit and dissemination of scientific research documents, whether they are published or not. The documents may come from teaching and research institutions in France or abroad, or from public or private research centers.
L'archive ouverte pluridisciplinaire HAL, est destinée au dépôt et à la diffusion de documents scientifiques de niveau recherche, publiés ou non, émanant des établissements d'enseignement et de recherche français ou étrangers, des laboratoires publics ou privés. 


\section{An in-vitro bioassay to assess the potential global toxicity of waters on 2 spermatogenesis: a pilot study}

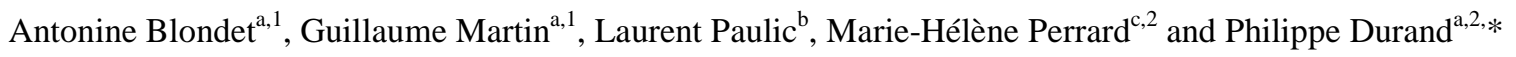
Environ Sci Pollut Res Int. 2021 Jan 25. doi: 10.1007/s11356-021-12480-1. Online ahead of print.PMID: 33495953

${ }^{a}$ Kallistem, Vétagrosup, 1 Avenue Bourgelat, 69280 Marcy-l’Etoile, France

philippe.durand@kallistem.com, antonine.blondet@kallistem.com, guillaume.martin@kallistem.com,

${ }^{\mathrm{b}}$ Tame-Water, 3 rue jean Jaurès 85000 La Roche sur Yon, France lpaulic@tame-water.com marie-helene.perrard-durand@ @inserm.fr

*Corresponding author: philippe.durand@kallistem.com,

${ }^{1}$ These authors contributed equally to this study.

\section{Abbreviations}

Trans-epithelial electrical resistance: TEER; 1,3-dinitrobenzene (DNB); checkpoint kinase 2: CHK2; DEAD-box helicase 4: VASA; testis specific histone 2B: TH2B; Stathmin 1: STMN1; Transition Protein 1: TP1; Transition Protein 2: TP2; Protamine-3: PRM3; Androgen receptor: AR; Estrogen receptor alpha: ER $\alpha$; 
Abstract

27 Many toxicants are present in water as a mixture. Male infertility is one of the environmental impacts in developed countries. Using our rat seminiferous tubule culture model, we evaluated the effects of waters of different origins, on several parameters of the seminiferous epithelium. Concentrated culture medium was diluted with the waters to be tested (final concentrations of the tested waters were between 8 and $80 \%$ ). The integrity of the blood-testis barrier was assessed by the trans-epithelial electric resistance (TEER). The levels of mRNAs specific of Sertoli cells, of cellular junctions, of each population of germ cells, of androgen receptor, of estrogen receptor $\alpha$ and of aromatase were also studied. We report, here, the results obtained with ten waters, some of them possessing a negative effect on spermatogenesis. The results showed that according to the tested waters, their effects on the parameters studied might be quite different indicating many different mechanisms of toxicity, including some endocrine disrupting effects. It has been reported that men with impaired semen parameters have an increased mortality rate suggesting semen quality may provide a fundamental biomarker of overall male health. Hence, we have developed a relevant in vitro bioassay allowing to evaluate the potential toxicity of different types of waters on male fertility and to assess some aspects of their mechanism of action. In addition to the TEER measure, the number and/or the identity of the studied mRNAs can be largely increased and/or modified, thus enhancing the possibility of using this model as a "warning system".

\section{Keywords}

Water quality, in vitro bioassay, methods, spermatogenesis, blood-testis barrier integrity, endocrine disrupting effects, global toxicity

(1)

(1)




\section{Introduction}

A large number of environmental factors can pollute air, water and food and may potentiate each other when present as a mixture (Cotton et al. 2016; Durand et al. 2017, 2020). Numerous studies suggest a decline in semen quality in some parts of the world (Carlsen et al. 1992; Auger et al. 1995; Adamopoulos et al. 1996; Van Waeleghem et al. 1996; Lackner et al. 2005; Sripada et al. 2007; Shine et al. 2008; Mukhopadhyay et al. 2010; Geoffroy-Siraudin et al. 2012). This might occur in response to adverse environmental factors (Gabrielsen and Tanrikut 2016).

Using our rat seminiferous tubule culture model (Bio-AlteR $®$ ), which has been carefully validated on both a physiological and a "physio-toxicological" point of view (Geoffroy-Siraudin et al. 2010; Goldstein et al. 2016), we have developed a method to assess the potential impact of waters on spermatogenesis and to explore some aspects of their mechanism of action. For this purpose, the integrity of the blood-testis barrier was determined by measuring the trans-epithelial electric resistance (TEER). Indeed, we, and others, have shown that several toxicants which may be present in the environment can alter the blood-testis barrier (Carette et al. 2015; Gao et al. 2015; Goldstein et al. 2016). Also, the expression of genes specific of Sertoli cells, of cellular junctions, and of each population of germ cells was studied by reverse transcription-quantitative polymerase chain reaction (RT-qPCR). Similarly, the expressions of Androgen receptor (AR), of Estrogen receptor alpha (ER $\alpha)$ and of aromatase were investigated. Hence, in order to validate this in vitro bioassay, in the present manuscript we report the results obtained with ten waters from different origins.

\section{Materials and Methods}

\section{2-1 Animals}

Experiments were performed with 20-22-day-old male Sprague-Dawley rats having undergone no treatment. Testes from six to ten rats were pooled. The experimental protocol was designed in compliance with recommendations of the European Economic Community (EEC) (86/609/EEC) for the care and use of laboratory animals. 


\section{2-2 Preparation and culture of seminiferous tubule segments}

Small seminiferous tubule segments were seeded, at a high density, in bicameral chambers and cultured in a serum-free culture medium as previously described (Geoffroy-Siraudin et al. 2010; Carette et al. 2015; Goldstein et al. 2016). Incubations were carried out at $33^{\circ} \mathrm{C}$ in a water-saturated atmosphere of $95 \%$ air and $5 \% \mathrm{CO} 2$. Each culture was carried out in four to seven replicates for 10 to 21 days, either in the absence or presence of the water sample to be tested. The complete culture medium was 15mM Hepes-buffered F12 / DMEM supplemented with $10 \mu \mathrm{g} / \mathrm{ml}$ gentamycin, $10 \mu \mathrm{U} / \mathrm{ml}$ nystatin, $10 \mu \mathrm{g} / \mathrm{ml}$ insulin, $10 \mu \mathrm{g} / \mathrm{ml}$ human transferrin, $10^{-4} \mathrm{M}$ vitamin $\mathrm{C}$, $10 \mu \mathrm{g} / \mathrm{ml}$ vitamin $\mathrm{E}, 10^{-7} \mathrm{M}$ testosterone, $3.310^{-7} \mathrm{M}$ retinoic acid, $3.310^{-7} \mathrm{M}$ retinol, $10^{-3} \mathrm{M}$ pyruvate (Sigma) and $1 \mathrm{ng} / \mathrm{ml} \mathrm{FSH}(\mathrm{NIH}$, Bethesda, MD).

\section{2-3 Preparation of the culture medium}

Complete 5X culture medium was made by dissolution of DMEM / F12, 15mM Hepes-buffered, in powder in Versol water. The $\mathrm{pH}$ of this $5 \mathrm{X}$ medium was adjusted to a physiological $\mathrm{pH}: 7.1 \pm 0.2$ in order to avoid characterizing the effects of a difference in $\mathrm{pH}$. Then, the medium was filtered through a $0.2 \mu \mathrm{m}$ filter. Concentrated culture medium was diluted five-fold with either Versol water (control) or the water to be tested giving a final concentration of the tested water of $80 \%(\mathrm{v} / \mathrm{v})$. For those waters to be tested at lower concentrations, they were first diluted with Versol water before being added to the concentrated culture medium (final $\mathrm{pH}$ between 6.9 and 7.3). The waters to be tested were present from day 2 of culture and only in the basal compartment of the bicameral chamber. Only the basal media [prepared without (control) or with the water to be tested] were renewed every 2-3 days. To test the effect of 1,3dinitrobenzene (DNB), a stock solution at $10 \mathrm{mg} /$ $\mathrm{ml}$ was prepared in $100 \%$ ethanol. The final concentration tested in the culture medium was $10 \mu \mathrm{g} / \mathrm{ml}(0.1 \%$ ethanol).

\section{2-4 Trans-epithelial electrical resistance}

TEER measurement was performed as previously (Carette et al. 2015; Durand et al. 2017) with an EVOM2 (World Precision Instruments, Florida, USA). The culture was equilibrated at room temperature before the assay. The TEER was calculated according to the following equation: TEER $=(\mathrm{R}$ total-R control $) . \mathrm{A}(\Omega \mathrm{cm} 2)$, where $\mathrm{R}$ total is the resistance measured, $\mathrm{R}$ control is the resistance of the control insert (insert alone with the culture medium), and $\mathrm{A}$ is the surface area of the insert. 

(https://biostatgv.sentiweb.fr/?module=tests/anova).

\section{2-5 RT-qPCR}

117 Four to seven wells were pooled and total RNA was extracted from cultured seminiferous tubules, at the end 118 of the culture (between day 10 and day 20), using TRI-REAGENT (Euromedex, Souffelweyersheim, France) according to the manufacturer's protocol. All samples were treated by DNase I before the reverse transcription; first-strand cDNA was synthesized from $1 \mu \mathrm{g}$ RNA with Super Script III in the presence of oligodT and Random Primer (all from Thermo Fisher Scientific, Villebon sur Yvette, France). Real-time PCR was performed in a StepOnePlus instrument (Applied Biosystems) by using SYBR-Green (Qiagen, Courtaboeuf, France). control. The results are expressed in \% expression for each gene studied: absolute value of the condition treated / absolute value of the control (Carette et al. 2015). The absolute value: 2 [-moyCT] was calculated for each gene studied as well as for the housekeeping gene (16S). The value obtained for each gene studied was divided by the value obtained for the 16S mRNA. Pooling of wells did not permit an estimate of measurement error in the RT-qPCR data, thus, statistical analysis was not performed. Based on our experience, we consider that a condition causes $(i)$ an increase in the level of expression when the value of the measure is greater than $130 \%$ of the value of the control; (ii) a decrease of the level of expression when the value of the measure is lower than $70 \%$ of the value of the control. 
Table 1: Sequences of the primers used for RTqPCR

\begin{tabular}{|l|l|l|l|}
\hline & fwd-5 & rev-5' & $\begin{array}{l}\text { Reference } \\
\text { Sequence }\end{array}$ \\
\hline CHK2 & TGCTGGAGCCTAGGAGTCAT & TCATGTGCTCATCCTGAAGC & NM_053677.1 \\
\hline VASA & GATGCACCACCGGCAATTTT & TTCCCAGACCCTGTTTGAGC & NM_001077647.1 \\
\hline Integrin $\alpha 6$ & TCGGTCTCTGGAGTCGCTAA & GCCGTGCCGAGGTTTTAAG & NM_053725.1 \\
\hline TH2B & GATGCCGCGAAGAGAGTTAC & GGTCGAGCGCTTGTTGTAAT & NM_022643.1 \\
\hline Stathmin & AAGGATCTTTCCCTGGAGGA & TTCTCCTCTGCCATTTTGCT & NM_017166.1 \\
\hline TP1 & CGACCAGCCGCAAACTAAAG & ATCATCGCCCCGTTTCCTAC & NM_017056.2 \\
\hline TP2 & GGCCTCAAAGTCACACCAAT & CTTGCTCACTTTCCCTTCCA & NM_017057.2 \\
\hline PRM3 & GTGGCCTGTGTGAGTCAAGA & CCTCAGCACCATCTTGCTTT & NM_001002855.2 \\
\hline AR & GTGTCGTCTCCGGAAATGTT & GGAATCAGGCTGGTTGTTGT & NM_012502.1 \\
\hline ER $\alpha$ & CATCGATAAGAACCGGAGGA & AAGGTTGGCAGCTCTCATGT & NM_012689.1 \\
\hline Aromatase & TCTCCAGATTCGGCAGCAAG & ATAAGAACAGGGCCCGTCAG & NM_017085.2 \\
\hline TJP1 & TGCTCCAGCAGGTCCTAAGT & TGGTAGCTGAGGGCAGAACT & NM_001106266.1 \\
\hline Claudin-11 & CTGGTGGACATCCTCATCCT & GCGCATACAGGAAACCAGAT & NM_053457.2 \\
\hline Occludin & GAGGGTACACAGACCCCAGA & CAGGATTGCGCTGACTATGA & NM_031329.2 \\
\hline Connexin 43 & TCCTTGGTGTCTCTCGCTTT & GAGCAGCCATTGAAGTAGGC & NM_012567.2 \\
\hline Clusterin & TTCATTCCCTCCAGTCCAAG & CACGAGAGGGGACTTCTGAG & NM_053021.2 \\
\hline Vimentin & AGATCGATGTGGACGTTTCC & CACCTGTCTCCGGTATTCGT & NM_031140.1 \\
\hline 16S & AGTCTTCGGACGCAAGAAAA & AGCCACCAGAGCTTTTGAGA & NM_001169146.1 \\
\hline
\end{tabular}

\section{3-1 Effect of different dilutions of effluent waters on the TEER and the levels of TP1 mRNA}

In a first set of experiments serial dilutions of three hospital effluent waters (Poitou Charente region, France) from the main building of the hospital (standard hospitalizations from general medicine: $24 \%$ of total flow);

Water C: an effluent from the regional cancer center (14\% of total flow).

Measurements of the TEER showed clear dose- and time- dependent effects on the integrity of the bloodtesticular barrier (Fig1a). For every water, at the lower concentration tested (8\%), a TEER greater than that of the control was observed on days 8 and 10 (all $p \leq 0.001$ ). By contrast, for the higher concentration (80\%) of waters $\mathrm{B}$ and $\mathrm{C}$, the TEER was lower than the control from day 4 to day $10(\mathrm{p} \leq 0.001)$. These effects were associated to 


\section{3-2 Effect of 3 different hospital tap waters from the Ile de France region (tested at the concentration of} $80 \%$ ) on the TEER and the levels of TP1, TP2 and PRM3 mRNAs

In this series of experiments, DNB was included as a positive control in order to validate the responsiveness and the sensitivity of the culture (Fig. 2a). Indeed, DNB is a powerful testicular toxicant. In the Bio-AlteR ${ }^{\circ}$ rat model, we have shown that DNB exerts a direct toxic effect on Sertoli cells and germ cells and alters the TEER (Goldstein et al. 2016). In the present experiment, DNB at $10 \mu \mathrm{g} / \mathrm{ml}$ reduced the TEER from day 9 to day 19 (between 68 and $73 \%$ of the control, $\mathrm{p} \leq 0.05$ to $\mathrm{p} \leq 0.001$ ), and reduced dramatically the expression of the mRNAs of TP1, TP2 and PRM3 (all less than $1 \%$ of the control values, data not shown). For hospital tap waters I, II, and III no change of the TEER was ever observed (Fig. 2a). Nevertheless, hospital tap waters I and II increased the amounts of TP1, TP2 and PRM3 mRNAs (between 137 and 166\% of the control). By contrast, the amounts of mRNAs of TP1, TP2 and PRM3 were decreased (61\%, 48\% and $67 \%$ of the control respectively) by hospital tap water III (Fig. 2b).

\section{3-3 Effect of four drinking waters on the TEER and on the levels of some "specific" mRNAs}

In order to refine the above results, in the last set of experiments presented here, we increased the number of mRNAs investigated. For this purpose, we evaluated the effects on spermatogenesis of two tap waters (1 and 2) from different sources of the area of Lyon (France) and of two plastic bottled mineral waters (3 and 4). All these waters were tested at the concentration of $80 \%$.

\section{3-3-1 Effect on the TEER}

As shown in Fig. 3a, the TEER of tap water 1 was higher than the control on days 8 and 10 (123 and $127 \%$ respectively, $\mathrm{p} \leq 0.01$ ), but lower at the end of the culture (54 to $82 \%$ from day 15 to day $20, \mathrm{p} \leq 0.01$ to $\mathrm{p} \leq 0.001)$. By contrast, the TEER of tap water 2 ranged between $90 \%$ and $98 \%$ of the value of the control water until day 13, but was slightly lower from day 15 until day 20 (between 75 and $78 \%$ of control $\mathrm{p} \leq 0.05$ to $\mathrm{p} \leq 0.01$ ). For plastic bottled mineral waters (Fig. 3b), the TEER of water 3 was never less than $85 \%$ of the control, whereas for water 4 it was lower only from day 13 to day 17 ( 71 to $81 \%$ of control $p \leq 0.01$ to $p \leq 0.001$ ). 


\section{3-3-2 Effect on the relative levels of some "specific" mRNAs}

For tap water 1 the clear biphasic modifications of the TEER were associated, on day 20 of culture, to changes in the expression, of some genes specific of tight (claudin-11 and occludin: 52\% and 40\% of control) or gap junctions ( $71 \%$ for connexin 43 ) (fig. 4). Smaller changes were observed for tap water 2 and for the two mineral waters 3 and 4 (61\% for TJP1 for water 2); (53 and 68\%, for claudin-11 for waters 3 and 4 respectively) and $144 \%$ for connexin 43 for water 4$)$.

The mRNAs of clusterin and of vimentin, specific of the Sertoli cells, were not modified by any water, but a slight increase (133\% of the control for vimentin) for mineral water 4 (Fig. 5). Conversely, more changes were observed at the level of germ cells specific mRNAs. In spermatogonia, CHK2 mRNA was decreased by tap water 2 and mineral water 3 (55 and 54\% of the control respectively), and VASA mRNA (between 54 and $61 \%$ of the control for tap waters 1,2 and mineral water 4$)$. No change was ever observed for integrin $\alpha 6$ mRNA. In spermatocytes, stathmin mRNA was decreased only by tap water 1 ( $50 \%$ of the control), and TH2B mRNA by tap water 2 (65\% of the control). TP1, TP2 and PRM3 mRNAs, specific of round spermatids (Marret et al. 1998; Grzmil et al. 2008) were all greatly decreased by tap water 1 (between 29 and $41 \%$ of control). TP1 mRNA was also decreased by tap water 2 and the two mineral waters (between 56 and 69\% of control), and PRM3 mRNA by the mineral waters 3 and 4 (70 and $63 \%$ of the control respectively).

As shown in Fig. 6, only mineral water 3 decreased the mRNA of AR (59\% of the control). No change was ever observed at the level of Er $\alpha$ mRNA, whereas aromatase mRNA was decreased by all the tested waters (between 55 and $68 \%$ of control).

\section{Discussion}

Methods for assessing the total impact, on water quality, of all the chemicals present are clearly needed (Murk et al. 2002; Bain et al. 2014; Escher et al. 2014; Di Paolo et al. 2016; Välitalo et al. 2016, 2017; van der Oost et al. 2017a, b). The present bioassay, which is based on primary mammalian cultured cells, associates a functional approach (TEER), with a quantification of some mRNAs which are specific of the different types of cells.

Indeed, in this model, the assessment of the TEER is performed in cultures associating both the somatic cells and the germ cells of the seminiferous epithelium. It has been shown that disruption of Connexin 43 induces an increase of the transcription of some tight junction proteins which results in an increase of the TEER (Carette et 
al. 2010, 2015) whereas an alteration of tight junctions leads to a decrease of the TEER (Janecki et al. 1992; Hu et al. 2014). This would suggest that at the lower concentrations tested, waters A, B and C disrupted mainly Connexin- based gap junctions, whereas at the higher concentrations they disrupted both gap junctions and tight junctions. Of importance, in this study, we show that some waters may have an impact on some parameters involved in the process and/ or regulation of spermatogenesis, directly at the level of the seminiferous epithelium, including some endpoints related to possible endocrine disrupting effects.

It is clear that according to the tested waters, their effects on the parameters studied may be quite different indicating many different mechanisms of toxicity leading to decrease or increase in the mRNA levels of TP1, TP2 or PRM3. Moreover, whereas for the hospital effluent waters A, B and C there was a rather good correlation between the TEER and the amounts of TP1 mRNA, this was clearly not the case for the hospital tap waters I, II and III. The absence of an effect on the TEER suggests either no effect on the blood-testis barrier or the occurrence of an equilibrium resulting from a disruption of Connexin 43 associated with some alteration of the tight junctions. The important impact on the TEER of tap water 1 was associated to rather important modifications of the expression of the mRNAs specific of some cellular junction proteins including a decrease in Connexin 43 mRNA. At the level of the blood testis-barrier, Connexin 43, a constitutive protein of gap junctions, is highly intermingled with proteins of tight (Occludin, Claudin, Zonula occludens-1...) and adherens junctions (N-cadherin) (Pointis and Segretain 2005). Occludin- and Claudin-11-based tight junctions are the major components of the blood-testis barrier (Morrow et al. 2010). Recent studies have revealed that the gap junction protein Connexin 43 is crucial for spermatogenesis (Pointis et al. 2005; Brehm et al. 2007; Sridharan et al. 2007; Vinken et al. 2010). In addition, it has been reported that chemicals could alter Sertoli/germ cell interaction, through disruption of Connexin 43-based gap junctions, and affect the other junction types leading to some destabilization of the blood-testis barrier (Li et al. 2009, 2010; Carette et al. 2010).

Therefore, the measurement of TEER in the present model of culture appears as a first, simple and sensitive, but not sufficient, mean to evaluate the incidence of a water sample on the spermatogenic process. The great modifications of the values of the TEER induced by tap water 1 were clearly associated to changes in the expression of genes specifically expressed by meiotic (spermatocytes) and post meiotic (round spermatids) cells which are able to differentiate only in the presence of a functional blood-testis barrier (Mruk and Cheng 2015). Despite lower modifications of the TEER values, tap water 2 and mineral waters 3 and 4 also induced changes in the amounts of mRNAs of several junctional proteins. These changes were associated to decreased levels of some mRNAs specific of post-meiotic cells indicating alteration of the meiotic step. The amounts of the mRNAs 
of CHK2 and of VASA, specific of the mitotic phase of spermatogenesis, were also decreased by some of the drinking waters 1 to 4 . However, it is important to underline that no change was ever observed for those mRNAs of integrin $\alpha 6$ suggesting no alteration of the population of the spermatogonial stem cells (Shinohara et al. 1999). Only very few, if any, changes at the level of the mRNAs of vimentin or clusterin, specific of the Sertoli cells, were induced by either drinking water 1 to 4 .

Rather surprising was the decrease in mRNAs of aromatase induced by drinking waters 1 to 4 . The Sertoli cells are the main source of estrogens in immature rats, whereas in adults, estrogens are synthesized by the Leydig and the germ cells (Carreau et al. 2009). This decrease of the aromatase expression in the adult Sertoli cells has been suggested to result from a negative control of Sertoli cell aromatase expression by germ cells via paracrine regulatory factors (Boitani et al. 1981; Silandre et al. 2007; Bouraïma-Lelong et al. 2010). Hence it is tempting to suggest some endocrine disrupting activity of these 4 drinking waters. Similarly, the decrease in AR mRNAs induced by mineral water 3 might indicate an anti-androgenic effect of this plastic bottled mineral water, and/or of the plastic of the bottle itself.

In this work we have developed a global relevant and sensitive biological approach to evaluate the potential global toxicity of waters on male fertility and to assess some aspects of their mechanism of action. Further, it should be underlined that most of the growth factors, cytokines, neurotrophins and steroid hormones produced within the testis, and necessary for spermatogenesis, are widely expressed in the organism and/or necessary for the regulation of other vital functions. For instance, (i) the glial cell-derived neurotrophic factor (GDNF) has been observed in the central nervous system (Du and Dreyfus 2002) and peripheral organs including the kidneys, lungs, blood, and testes (Suter-Crazzolara and Unsicker 1994; Trupp et al. 1995; Suvanto et al. 1996); (ii) the receptor tyrosine kinase c-Kit and its ligand Stem Cell Factor (SCF) are involved in haemopoiesis, melanogenesis and spermatogenesis (Ashman 1999; Rossi et al. 2000). In this line, it has been reported that men with impaired semen parameters have an increased mortality rate suggesting semen quality may provide a fundamental biomarker of overall male health (Jensen et al. 2009; Eisenberg et al. 2014). Taken together, these features suggest the possibility of using this in vitro bioassay as a "warning system". 


\section{Declarations}

\section{-Ethical Approval}

278 The experimental protocol was designed in compliance with recommendations of the European Economic Community (EEC) (86/609/EEC) for the care and use of laboratory animals.

\section{-Consent to Participate}

All authors consented to participate to this work.

\section{-Consent to Publish}

All authors consented to publish this work.

\section{-Availability of data and materials}

The datasets used and/or analyzed during the current study are available from the corresponding author on reasonable request.

\section{-Competing Interests}

The authors declare no competing interest.

\section{-Funding}

The company KALLISTEM funded all the experiments described in this Manuscript.

\section{-Authors Contributions}

Conceived and designed the experiments: LP, MHP and PD. Performed the experiments: AB, GM and PD.

Analyzed the data: AB, GM, MHP and PD. Contributed reagents/materials/analysis tools: LP. Contributed to the writing of the manuscript: MHP and PD.

\section{-Acknowledgements}

Ovine FSH-20 was obtained through the National Hormone and Peptide Programme, the National Institute of 


\section{References}

Adamopoulos DA, Pappa A, Nicopoulou S, et al (1996) Seminal volume and total sperm number trends in men attending subfertility clinics in the Greater Athens area during the period 1977-1993. Human Reproduction 11:1936-1941. doi: 10.1093/oxfordjournals.humrep.a019520

Ashman LK (1999) The biology of stem cell factor and its receptor C-kit. International Journal of Biochemistry and Cell Biology 31:1037-1051. doi: 10.1016/S1357-2725(99)00076-X

Auger J, Kunstmann JM, Czyglik FC, Jouannet P (1995) Decline in semen quality among fertile men in paris during the past 20 years. New England Journal of Medicine 332:281-285. doi: 10.1056/NEJM199502023320501

Bain PA, Williams M, Kumar A (2014) Assessment of multiple hormonal activities in wastewater at different stages of treatment. Environmental Toxicology and Chemistry 33:2297-2307. doi: 10.1002/etc.2676

Boitani C, Ritzén EM, Parvinen M (1981) Nhibition of rat sertoli cell aromatase by factor(s) secreted specifically at spermatogenic stages VII and VIII. Molecular and Cellular Endocrinology 23:11-22. doi: 10.1016/0303-7207(81)90113-1

Bouraïma-Lelong H, Vanneste M, Delalande C, et al (2010) Aromatase gene expression in immature rat Sertoli cells: Age-related changes in the FSH signalling pathway. Reproduction, Fertility and Development 22:508-515. doi: 10.1071/RD09168

Brehm R, Zeiler M, Rüttinger C, et al (2007) A sertoli cell-specific knockout of connexin43 prevents initiation of spermatogenesis. American Journal of Pathology 171:19-31. doi: 10.2353/ajpath.2007.061171

Carette D, Blondet A, Martin G, et al (2015) Endocrine Disrupting Effects of Noncytotoxic Doses of Carbendazim on the Pubertal Rat Seminiferous Epithelium: An Ex Vivo Study. Applied In Vitro Toxicology 1:289-301

Carette D, Weider K, Gilleron J, et al (2010) Major involvement of connexin 43 in seminiferous epithelial junction dynamics and male fertility. Developmental Biology 346:54-67. doi: 10.1016/j.ydbio.2010.07.014

Carlsen E, Giwercman A, Keiding N, Skakkebaek NE (1992) Evidence for decreasing quality of semen during past 50 years. BMJ (Clinical research ed) 305:609-13

Carreau S, Delalande C, Galeraud-Denis I (2009) Mammalian sperm quality and aromatase expression. Microscopy Research and Technique 72:552-557. doi: 10.1002/jemt.20703

Cotton J, Leroux F, Broudin S, et al (2016) Development and validation of a multiresidue method for the analysis of more than 500 pesticides and drugs in water based on on-line and liquid chromatography coupled to high resolution mass spectrometry. Water Research 104:20-27. doi: 10.1016/j.watres.2016.07.075

Di Paolo C, Ottermanns R, Keiter S, et al (2016) Bioassay battery interlaboratory investigation of emerging contaminants in spiked water extracts - Towards the implementation of bioanalytical monitoring tools in water quality assessment and monitoring. Water Research 104:473-484. doi: 10.1016/j.watres.2016.08.018

Du Y, Dreyfus CF (2002) Oligodendrocytes as providers of growth factors. Journal of Neuroscience Research 68:647-654. doi: 10.1002/jnr.10245

Durand P, Blondet A, Martin G, et al (2020) Effects of a mixture of low doses of atrazine and benzo[a]pyrene on the rat seminiferous epithelium either during or after the establishment of the blood-testis barrier in the rat seminiferous tubule culture model. Toxicology in Vitro 62:104699. doi: 10.1016/j.tiv.2019.104699

Durand P, Martin G, Blondet A, et al (2017) Effects of low doses of carbendazim or iprodione either separately or in mixture on the pubertal rat seminiferous epithelium: An ex vivo study. Toxicology in Vitro 45:366373

Eisenberg ML, Li S, Behr B, et al (2014) Semen quality, infertility and mortality in the USA. Human Reproduction 29:1567-1574. doi: 10.1093/humrep/deu106

Escher BI, Allinson M, Altenburger R, et al (2014) Benchmarking organic micropollutants in wastewater, recycled water and drinking water with in vitro bioassays. Environmental Science and Technology 48:1940-1956. doi: 10.1021/es403899t

Gabrielsen JS, Tanrikut C (2016) Chronic exposures and male fertility: the impacts of environment, diet, and drug use on spermatogenesis. Andrology 4:648-661. doi: 10.1111/andr.12198

Gao Y, Mruk DD, Cheng CY (2015) Sertoli cells are the target of environmental toxicants in the testis-a mechanistic and therapeutic insight. Expert Opinion on Therapeutic Targets 19:1073-90. doi: $10.1517 / 14728222.2015 .1039513$

Geoffroy-Siraudin C, Dieudonné Loundou A, Romain F, et al (2012) Decline of semen quality among 10932 males consulting for couple infertility over a 20-year period in Marseille, France. Asian Journal of Andrology 14:584-590 
Geoffroy-Siraudin C, Perrard MH, Chaspoul F, et al (2010) Validation of a rat seminiferous tubule culture model as a suitable system for studying toxicant impact on meiosis effect of hexavalent chromium. Toxicological Sciences 116:286-296

Goldstein KM, Seyler DE, Durand P, et al (2016) Use of a rat ex-vivo testis culture method to assess toxicity of select known male reproductive toxicants. Reproductive Toxicology 60:92-103

Grzmil P, Boinska D, Kleene KC, et al (2008) Prm3, the Fourth Gene in the Mouse Protamine Gene Cluster, Encodes a Conserved Acidic Protein That Affects Sperm Motility1. Biology of Reproduction 78:958-67. doi: 10.1095/biolreprod.107.065706

Hu Y, Wang R, Xiang Z, et al (2014) Mixture effects of nonylphenol and di-n-butyl phthalate (monobutyl phthalate) on the tight junctions between Sertoli cells in male rats in vitro and in vivo. Experimental and Toxicologic Pathology 66:445-454

Janecki A, Jakubowiak A, Steinberger A (1992) Effect of cadmium chloride on transepithelial electrical resistance of sertoli cell monolayers in two-compartment cultures-A new model for toxicological investigations of the "Blood-testis" barrier in vitro. Toxicology and Applied Pharmacology 112:51-57

Jensen TK, Jacobsen R, Christensen K, et al (2009) Good semen quality and life expectancy: A cohort study of 43,277 men. American Journal of Epidemiology 170:559-565. doi: 10.1093/aje/kwp168

Lackner J, Schatzl G, Waldhör T, et al (2005) Constant decline in sperm concentration in infertile males in an urban population: Experience over 18 years. Fertility and Sterility 84:1657-1661. doi: 10.1016/j.fertnstert.2005.05.049

Li MWM, Mruk DD, Lee WM, Cheng CY (2009) Connexin 43 and plakophilin-2 as a protein complex that regulates blood-testis barrier dynamics. Proceedings of the National Academy of Sciences of the United States of America 106:10213-10218. doi: 10.1073/pnas.0901700106

Li MWM, Mruk DD, Lee WM, Cheng CY (2010) Connexin 43 is critical to maintain the homeostasis of the blood-testis barrier via its effects on tight junction reassembly. Proceedings of the National Academy of Sciences of the United States of America 107:17998-18003. doi: 10.1073/pnas.1007047107

Marret C, Avallet O, Perrard-Sapori MH, Durand P (1998) Localization and quantitative expression of mRNAS encoding the testis- specific histone TH2B, the phosphoprotein $\mathrm{p} 19$, the transition proteins 1 and 2 during pubertal development and throughout the spermatogenic cycle of the rat. Molecular Reproduction and Development 51:22-35

Morrow CMK, Mruk D, Cheng CY, Hess RA (2010) Claudin and occludin expression and function in the seminiferous epithelium. Philosophical Transactions of the Royal Society B: Biological Sciences 365:1679-1696. doi: 10.1098/rstb.2010.0025

Mruk DD, Cheng CY (2015) The mammalian blood-testis barrier: Its biology and regulation. Endocrine Reviews 36:564-591. doi: 10.1210/er.2014-1101

Mukhopadhyay D, Varghese AC, Pal M, et al (2010) Semen quality and age-specific changes: A study between two decades on 3,729 male partners of couples with normal sperm count and attending an andrology laboratory for infertility-related problems in an Indian city. Fertility and Sterility 93:2247-2254. doi: 10.1016/j.fertnstert.2009.01.135

Murk AJ, Legler J, Van Lipzig MMH, et al (2002) Detection of estrogenic potency in wastewater and surface water with three in vitro bioassays. Environmental Toxicology and Chemistry 21:16-23. doi: 10.1002/etc.5620210103

Pointis G, Fiorini C, Defamie N, Segretain D (2005) Gap junctional communication in the male reproductive system. Biochimica et Biophysica Acta - Biomembranes 1719:102-116. doi: 10.1016/j.bbamem.2005.09.017

Pointis G, Segretain D (2005) Role of connexin-based gap junction channels in testis. Trends in Endocrinology and Metabolism 16:300-306. doi: 10.1016/j.tem.2005.07.001

Rossi P, Sette C, Dolci S, Geremia R (2000) Role of c-kit in mammalian spermatogenesis. Journal of Endocrinological Investigation 23:609-615. doi: 10.1007/BF03343784

Shine R, Peek J, Birdsall M (2008) Declining sperm quality in New Zealand over 20 years. New Zealand Medical Journal 121:50-56

Shinohara T, Avarbock MR, Brinster RL (1999) beta1- and alpha6-integrin are surface markers on mouse spermatogonial stem cells. ProcNatlAcadSciUSA 96:5504-5509

Silandre D, Delalande C, Durand P, Carreau S (2007) Three promoters PII, PI.f, and PI.tr direct the expression of aromatase (cyp19) gene in male rat germ cells. Journal of Molecular Endocrinology 39:169-181. doi: 10.1677/JME-07-0046

Sridharan S, Simon L, Meling DD, et al (2007) Proliferation of Adult Sertoli Cells Following Conditional Knockout of the Gap Junctional Protein GJA1 (Connexin 43) in Mice1. Biology of Reproduction 76:804812. doi: 10.1095/biolreprod.106.059212

Sripada S, Fonseca S, Lee A, et al (2007) Trends in semen parameters in the northeast of Scotland. Journal of Andrology 28:313-319. doi: 10.2164/jandrol.106.000729 
Suter-Crazzolara C, Unsicker K (1994) GDNF is expressed in two forms in many tissues outside the CNS. NeuroReport 5:2486-2488. doi: 10.1097/00001756-199412000-00020

Suvanto P, Hiltunen JO, Arumäe U, et al (1996) Localization of glial cell line-derived neurotrophic factor (GDNF) mRNA in embryonic rat by in situ hybridization. European Journal of Neuroscience 8:816-822. doi: 10.1111/j.1460-9568.1996.tb01267.x

Trupp M, Rydén M, Jörnvall H, et al (1995) Peripheral expression and biological activities of GDNF, a new neurotrophic factor for avian and mammalian peripheral neurons. Journal of Cell Biology 130:137-148. doi: $10.1083 /$ jcb.130.1.137

Välitalo P, Massei R, Heiskanen I, et al (2017) Effect-based assessment of toxicity removal during wastewater treatment. Water Research 126:153-163. doi: 10.1016/j.watres.2017.09.014

Välitalo P, Perkola N, Seiler TB, et al (2016) Estrogenic activity in Finnish municipal wastewater effluents. Water Research 88:740-749. doi: 10.1016/j.watres.2015.10.056

van der Oost R, Sileno G, Janse T, et al (2017a) SIMONI (Smart Integrated Monitoring) as a novel bioanalytical strategy for water quality assessment: Part II-field feasibility survey. Environmental Toxicology and Chemistry 36:2400-2416. doi: 10.1002/etc.3837

van der Oost R, Sileno G, Suárez-Muñoz M, et al (2017b) SIMONI (smart integrated monitoring) as a novel bioanalytical strategy for water quality assessment: Part i-model design and effect-based trigger values. Environmental Toxicology and Chemistry 36:2385-2399. doi: 10.1002/etc.3836

Van Waeleghem K, De Clercq N, Vermeulen L, et al (1996) Deterioration of sperm quality in young healthy Belgian men. Human Reproduction 11:325-329. doi: 10.1093/HUMREP/11.2.325

Vinken M, Ceelen L, Vanhaecke T, Rogiers V (2010) Inhibition of gap junctional intercellular communication by toxic metals. Chemical Research in Toxicology 23:1862-1867. doi: 10.1021/tx100276f 

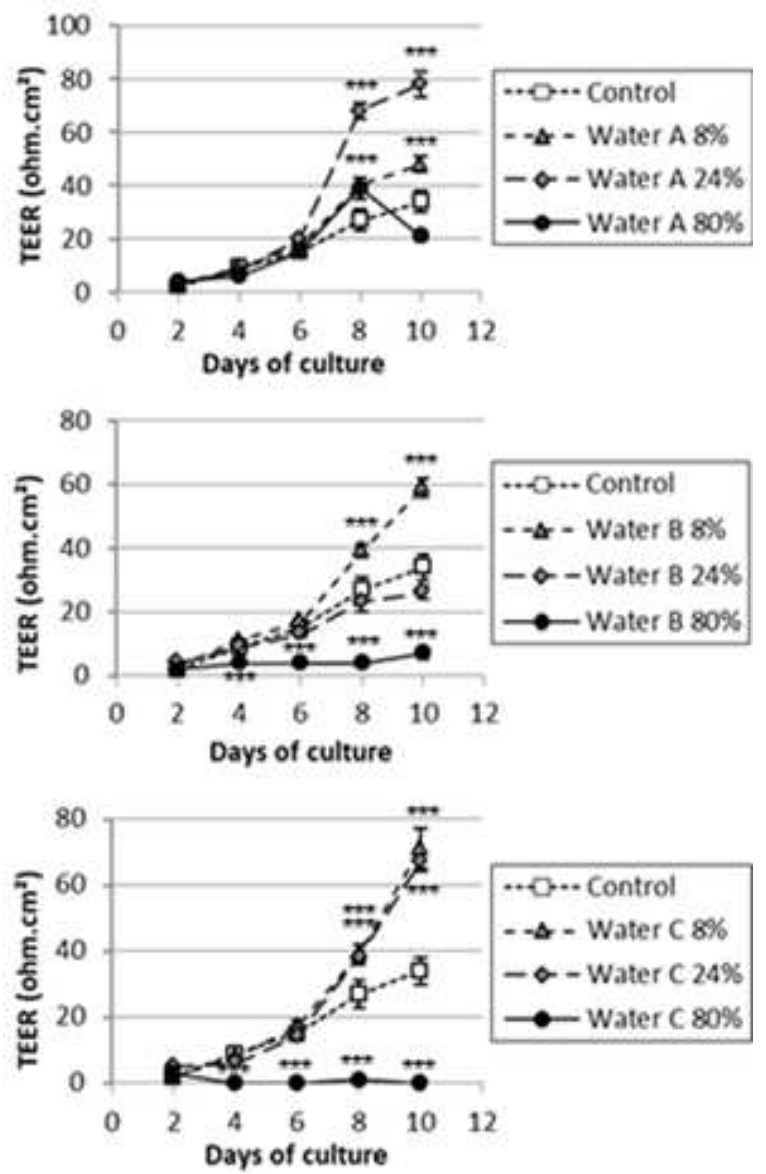

b

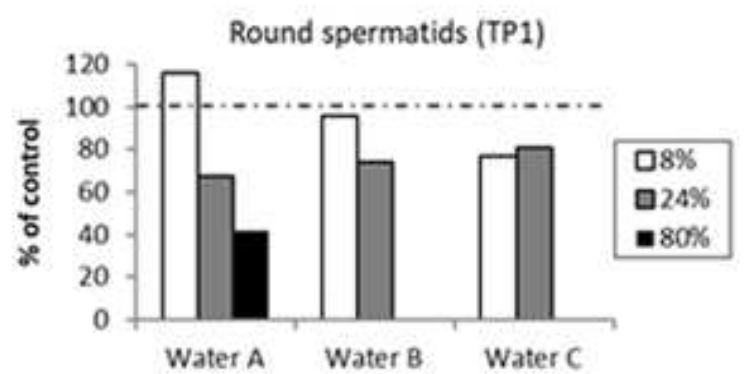

Figure 1: Effects of three hospital effluent waters on (panel a) the TEER of rat seminiferous tubules in culture and on (panel b) the mRNA-related qPCR product levels (\% of control) of TP1 (specific of round spermatids) after 10 days of culture.

468 Seminiferous tubule segments were cultured in control medium or in the presence of media made with A, B or C waters at $8 \%, 24 \%$ or $80 \%$.

470 (panel a): results are means \pm SEM of 4 wells per day for each condition.

471 Error bars reflect the standard error of the mean $(n=4) . * * p \leq 0.01, * * * p \leq 0.001$ by one-way ANOVA.

472 (panel b): results are means of 4 pooled wells. 
a

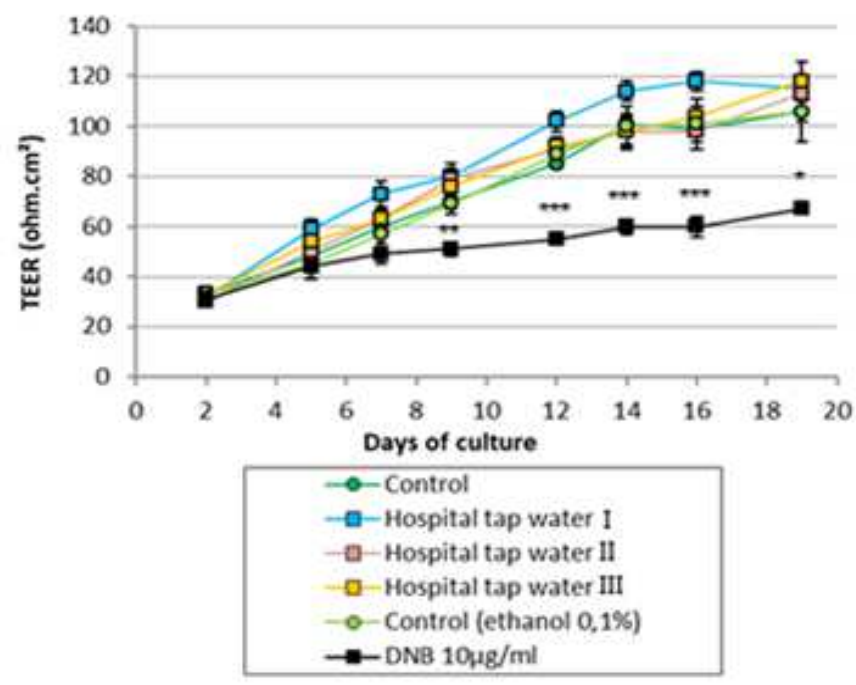

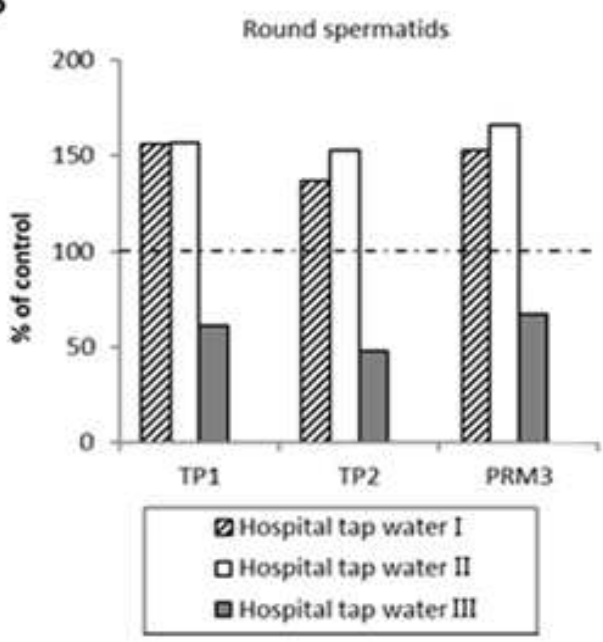

Figure 2: Effects of three hospital tap waters on (panel a) the TEER of rat seminiferous tubules in culture and on (panel b) the mRNA-related qPCR product levels (\% of control) of TP1, TP2 and PRM3 (specific of round spermatids) after 19 days of culture.

Seminiferous tubule segments were cultured in control medium or in the presence of media made with hospital tap waters I, II or III. The effect of DNB at $10 \mu \mathrm{g} / \mathrm{ml}$ was studied in parallel (in this case the control contained ethanol at $0.1 \%)$.

(panel a): results are means \pm SEM of 7 wells per day for each condition.

Error bars reflect the standard error of the mean $(n=7) . *^{*} \mathrm{p} \leq 0.01, * * * \mathrm{p} \leq 0.001$ by one-way ANOVA. (panel b): results are means of 7 pooled wells. 
a

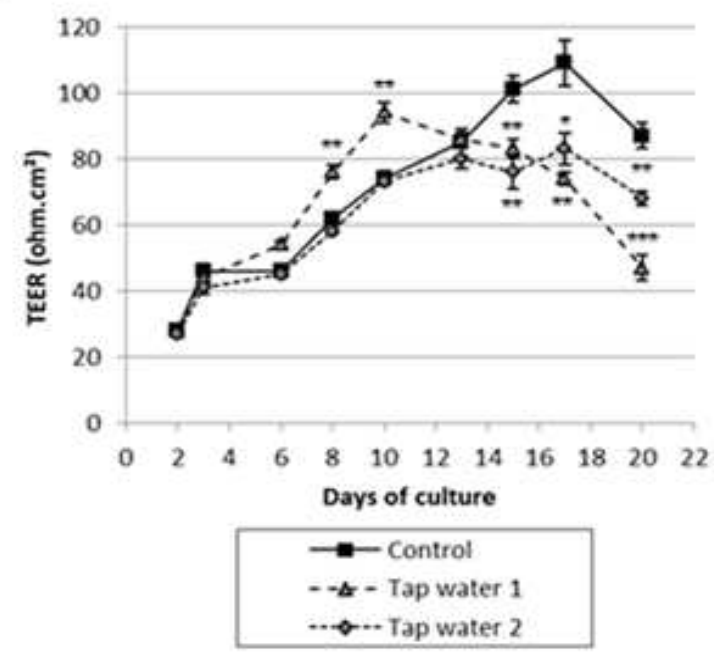

b

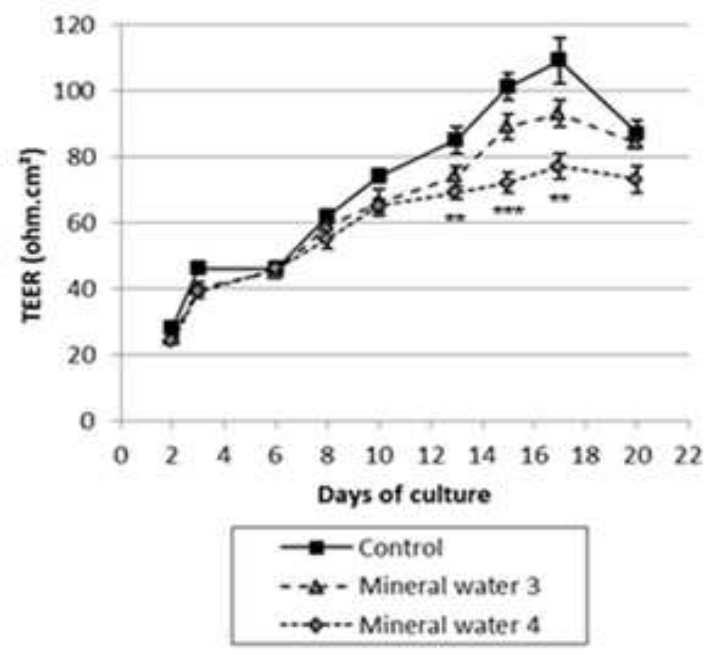

490

491

492

493

494

495

496

497

498

499

500

501

502

503

504

505

506

507

508

509

510

511

512

513

514

515

Figure 3: Effect of the four drinking waters on the TEER of rat seminiferous tubules in culture.

Seminiferous tubule segments were cultured in control medium or in the presence of media made with the tested waters.

(panel a): Tap water 1, Tap water 2

(panel b): mineral water 3 , mineral water 4

Results are means \pm SEM of 4 wells per day for each condition.

Error bars reflect the standard error of the mean $(n=4) . * p \leq 0.05, * * p \leq 0.01, * * * p \leq 0.001$ by one-way ANOVA. 
Tight junctions

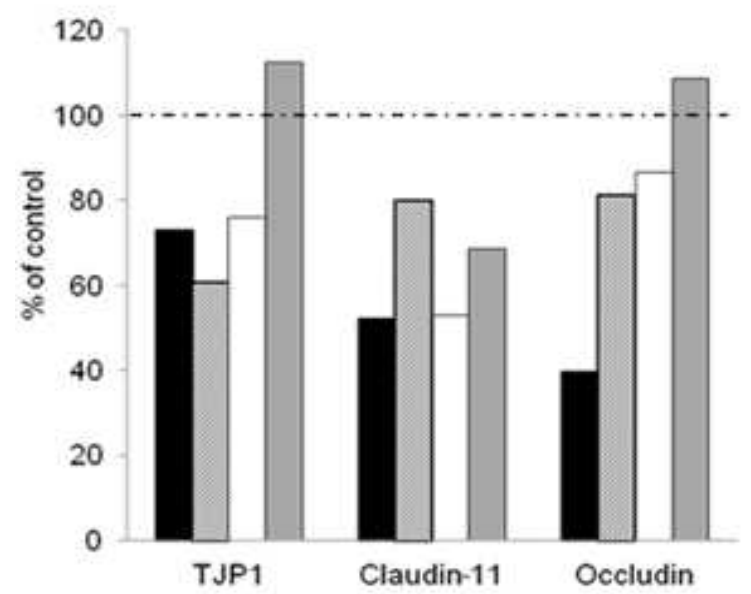

Gap junction

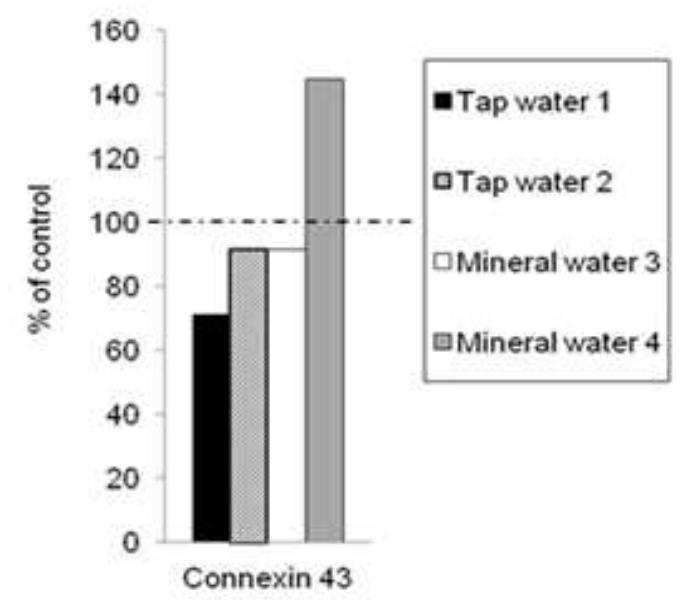

518 Figure 4: mRNA-related qPCR product levels (\% of control) of TJP1, claudin-11, occludin (specific of tight 519 junctions) and connexin 43 (specific of gap junctions) in seminiferous tubule segments cultured for 20 days in control medium or in the presence of media made with Tap water 1, Tap water 2, mineral water 3 or mineral water 4 . Results are means of 4 pooled wells for each condition. 

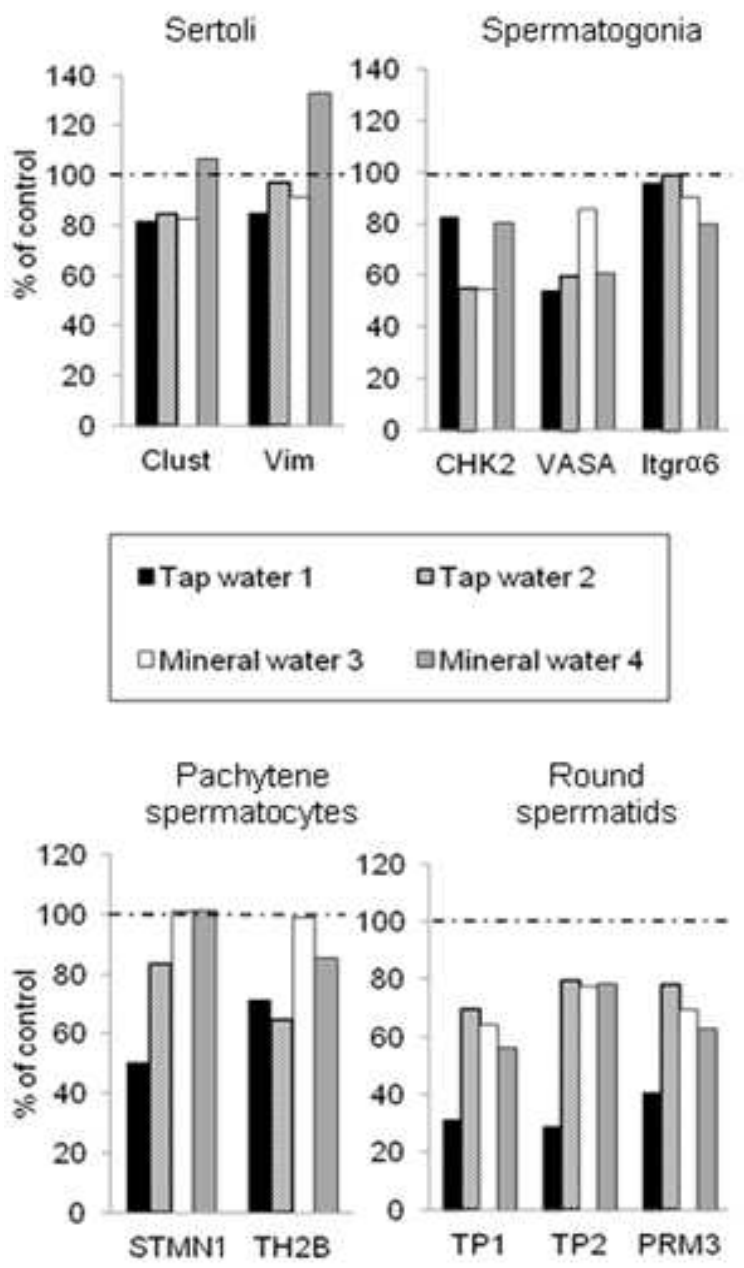

Figure 5: mRNA-related qPCR product levels (\% of control) of clusterin (Clust), vimentin (Vim) (specific of Sertoli cells), CHK2, VASA, integrin $\alpha 6$ (Itgra6) (specific of spermatogonia), STMN1, TH2B (specific of pachytene spermatocytes), TP1, TP2 and PRM3 (specific of round spermatids) in seminiferous tubule segments cultured for 20 days in control medium or in the presence of media made with Tap water 1, Tap water 2, mineral water 3 or mineral water 4 . Results are means of 4 pooled wells for each condition. 


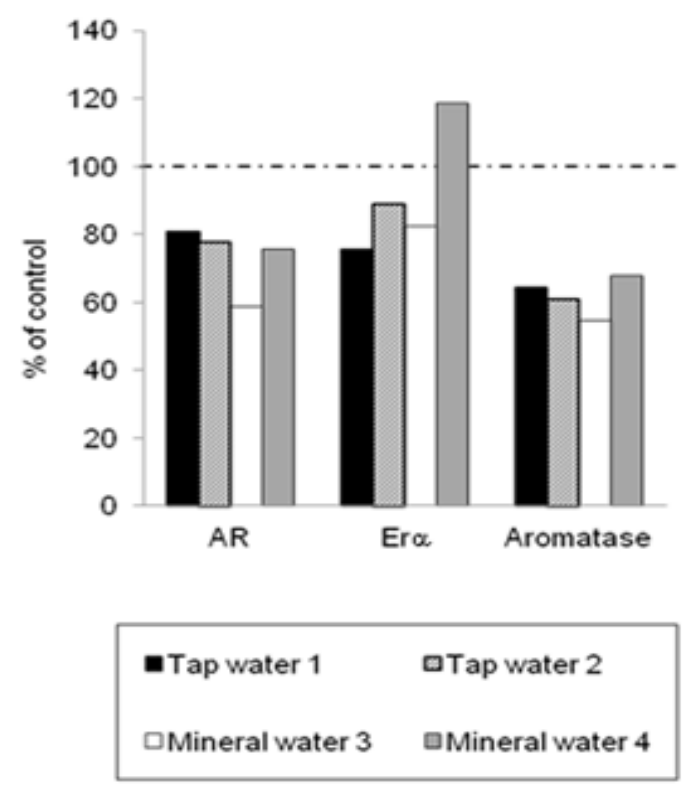

554 Figure 6: mRNA-related qPCR product levels (\% of control) of AR, Era and aromatase in seminiferous tubule 555 segments cultured for 20 days in control medium or in the presence of media made with Tap water 1, Tap water 5562 , mineral water 3 or mineral water 4 . Results are means of 4 pooled wells for each condition. 